\title{
Factors affecting success of biological agents used in controlling the plant-parasitic nematodes
}

\author{
Mahfouz M. M. Abd-Elgawad ${ }^{1 *}$ (D) and Tarique Hassan Askary²
}

\begin{abstract}
Biological control agents (BCAs) are increasingly used against various plant-parasitic nematode (PPN) pests and offer a favorable alternative to hazardous chemical nematicides. Yet, their lack of efficacy, inconsistent field performance, and/or unfavorable economic factors have generally relegated them to a relatively small sector of pesticide market. Efficacy and biocontrol success can be boosted via holistic grasping of soil biological and ecological factors. Therefore, such factors were highlighted to give better directions for their use. Main points discussed currently are considered to affect the transmission success of these BCAs so that their use must be a way forward in crop protection/pest management. These included improved sampling, grasping BCAs interactions with soil biota and ecology, cost-effective use of BCAs, genetic manipulation for better PPN control, grower acceptance and awareness-raising of BCA techniques, and commercial application.
\end{abstract}

Keywords: Biological control, Bionematicides, Nematodes, Integrated pest management, Sampling

\section{Background}

Plant-parasitic nematodes (PPNs) constitute so serious threats to growing crops in quantity and quality that the figures showing global averages of crop losses annually are staggering (Abd-Elgawad and Askary 2015). Biological control agents (BCAs) rank high among other PPN management options given mounting care to lessen the application of chemical nematicides with a clear aim at avoiding human health hazards and attaining pollution-free environment. In this respect, growing dissatisfaction with chemical pesticides has increased the research efforts to develop biological pesticides as important components of environmentally friendly pest management systems (Glare et al. 2012; Abd-Elgawad et al. 2017). Nevertheless, such biopesticides represented only 3.5\% ( $\$ 1.6$ billion) of the global pesticide market in 2009 (Lehr 2010). Moreover, most of their market is taken up by products for insect control sector. Sectors of microbial fungicides, herbicides, and nematicides have fewer shares (Wilson and Jackson 2013; Anonymous

\footnotetext{
*Correspondence: mahfouzian2000@yahoo.com

'Plant Pathology Department, National Research Centre, El-Behooth St. Dokki, Giza 12622, Egypt

Full list of author information is available at the end of the article
}

2019). Recently, the global biopesticides market was valued at USD 3147.1 million in 2018 and is expected to register a compound annual growth rate (CAGR) of 14.1\% during the forecast years 2019-2024 (Anonymous 2019). In order to enhance this CAGR, the less involved pesticide production sectors should be promoted as well.

In this vein, the huge research work of using biological control agents against PPNs is not exclusively carried out on high-value crops. However, for economic reasons, these BCAs are rarely marketed in low-value broad acre crops. Moreover, commercialization of bionematicides against PPNs has experienced highs and lows. Examples of apparent commercial successes include the formulation of active ingredients such as Purpureocillium lilacinus products, BioAct WP, BioAct WG, MeloCon, and NemOut, against a wide range of PPNs on economically important crops (Khan et al. 2006; Wilson and Jackson 2013); Myrothecium verrucaria products, DiTera DF, and DiTera WP, for use on a broad range of high-value fruit, vegetable, and ornamental crops with efficacy against a wide range of target PPN species (Wilson and Jackson 2013); and Bacillus firmus I-1582 and Nortica 5WG, for control of PPNs on turf grasses (Crow 2014; Abd-Elgawad and Askary 2018). But for every success, 
there have been numerous failures. In many cases, success was not achieved despite the nematode pests have shown promising susceptibility in laboratory or field plots (Askary and Martinelli 2015), e.g., a bionematicide containing in vitro produced Pasteuria usage product, Econem, was an ineffective treatment for the management of Belonolaimus longicaudatus on golf course turf. The product only decreased $B$. longicaudatus populations on a single sampling date in one of eight field trials (Crow et al. 2011). Timper (2014) reported examples of how agricultural practices can enhance or decrease the biological control of PPNs and other soil borne pests. She stressed that the conservation biological control of PPNs to protect or enhance their suppression may not be effective in all field sites because they are linked to indigenous antagonists. Wilson and Jackson (2013) pointed out the need and ability for scientists to publish negative data. Such data will enable the researchers to identify the deficiencies of the bionematicide, e.g., lack of efficacy, inconsistent field performance, and/or unfavorable economic factors. Thus, they can work on rectifying the shortcomings. This is especially timely with the current technological advances and major changes in the external environment, which have positively altered the outlook for biopesticides. Clearly, they are generally safe alternatives to hazardous chemicals (e.g., Glare et al. 2012; Abd-Elgawad et al. 2017). Nevertheless, the abovementioned deficiencies of the bionematicides have resulted in the failure of numerous biocontrol tactics against PPNs.

The substantial impact of soil biological and environmental factors on the success of biocontrol programs is undeniable. Hence, studies of soil biology should characterize the different relevant aspects of various organisms, especially in the plant rhizosphere by grasping their relative contribution in the biocontrol process as intimately interconnected and explicable only by reference to the whole. Likewise, ecological investigation should examine all biotic and abiotic factors that affect the biocontrol agent(s) as integral components for the plant health.

Hence, the present study reviews important factors currently deemed to influence BCA success. Our primary thrust is to elucidate factors that affect biocontrol potential against PPNs and focuses on recent developments and references, if applicable.

\section{Fostering commercial demand of biocontrol agents}

The remarkable operators for more commercial demands of a BCA are due to intrinsic, environmental, technological, societal, economic, and commercial items (Moosavi and Zare 2015; Labaude and Griffin 2018; Dutta et al. 2019). For instance, economic factors comprise the grower's sense to manage the PPN pests, the cost of biocontrol agent relative to other management options, the price of the commodity (e.g. per hectare), and the overall significance of the commodity in the agricultural market. Niche markets tend to be amenable to bionematicides use because both the crop value is high and the bionematicide product occupies a modest enough portion of the pesticide market for would-be rivals to shy away from registration costs and seek alternatives. Hence, low-value crops such as major row crops (e.g., maize, cotton, chickpea, and lentil) and some perennials (e.g., pigeon pea) are often unreachable for bionematicides marketing because the crop value is low and the market section is huge. These factors are interrelated, rendering more difficulty to solve the shortcomings. For instance, low BCA efficacy may result in a restricted product appeal, but effective cost application may adversely affect the efficiency of PPN control.

Stakeholders are tackling these issues via trying various approaches. Adequate surveys to find more effective, novel, or genetically manipulating BCA strains are in progress. Successful biopesticides could be the compounds produced by the microbes, rather than a BCA itself. Improved packaging in certain delivery systems that target specific sites of pest occurrence can also enhance tolerance to environmental stresses, increase persistence, and offer cost-effective tactics (Glare et al. 2012 and Abd-Elgawad 2019a). Delivery requires proper mass production of the microbes and their bioactives, favorable bionematicide formulation, and application to the target. Because production and formulation of biopesticides are usually kept as trade secrets or patents, their further development is frequently hindered. Abd-Elgawad (2019a) pointed out the need to use standardized procedures in developing such biopesticides in order to facilitate future reviews to be analytical, not just descriptive, and also offer building on them. Admittedly, BCAs occupy their own position as safe bionematicides, but for more pest control approaches, they are needed.

Therefore, the identification of research priorities for harnessing BCAs in sustainable agriculture in the context of grasping their relevant biology, ecology, interaction with other agricultural inputs, and mode of action is substantially required. The close examination of such targets to show the shortcomings and how to tackle or avoid them should widen the limited uptake of BCAs in pesticide markets. It can help in reducing $\mathrm{BCA}$ product costs and improving its efficacy and carryover effect which will stimulate their broader use in biocontrol. Therefore, the following section addresses the main topics currently considered to affect the transmission success of these BCAs to optimize their fitness, especially for lowvalue crops. 
Factors impacting application and success of BCAs Sampling

The adequate sampling of nematodes and their related fauna and flora in soil should be a pre-consideration. It includes sampling time, method, and process (Abd-Elgawad 2016a) to detect and diagnose PPN issues, if any. The nematode population density and genera found in these samples at preplanting should be determined. Nematode threshold levels or the common significance of the detected PPNs should be carefully assessed to determine the magnitude of applying BCAs. Biotic and abiotic factors relevant to nematode population level and plant damage should be considered because PPNs affect crop yields differently under various conditions. Sampling precision and accuracy, which usually increase with the more number of samples, are a substantial preconsideration. Yet, sampling intensity may consume time, effort, and money which may affect the decision of stakeholders. Therefore, Abd-Elgawad (2017a) reported different levels of sampling reliability associated with a fixed, cost-determined, sample size. Such grades may supply the decision maker with more informative facts on sampling approaches and their reliabilities. The recent advances in nematodes' sampling, extraction processes, identification, and counting constitute new approaches to optimize the abovementioned costs (e.g., Holladay et al. 2016; Campos-Herrera et al. 2019). Therefore, we adopted a precision and accuracy levels of sampling that is not less than $90 \%$ herein (Table 1). However, if such a reliability level was a cause for concern, it could be reduced by collecting, extracting, and counting more samples per plot. Abd-Elgawad (2016a) stressed that the higher precision may be adopted if the management threshold figure for the encountered nematode species lies within the confidence interval of the sample mean. Abd-Elgawad (2016a) could improve the assessment of nematode-sample size via iteration. Therefore, it is applied herein (Table 1) to set the improved sample size for important nematodes. For instance, the improved assessment of sample size required to record a 10\% reliability level for Meloidogyne incognita was 375 rather than 388 samples (Table 1).

Trait diversity of BCAs relative to soil biology and ecology Although the biological control of PPNs has been considered as a constitutive part of integrated pest management (IPM), comprehensive studies on the related soil biology-ecology are still desperately needed. Hence, many laboratory experiments on the efficacy of BCAs against PPNs frequently do not translate into success in the greenhouse and field. This is not surprising, given the complexity of the soil ecology and biology with myriad interacting biotic and abiotic factors which impact BCA and PPN survival. Although BCAs are usually applied in high numbers, only a small fraction of these succeed to suppress a PPN population. So, to enhance their capacity and efficacy, various methods of their adequate applications are utilized, and adequate environmental and biological factors are considered for BCAs to properly antagonist the PPNs.

Table 1 Improvement in minimum number of nematode samples needed to achieve a 10\% level of reliability as defined in terms of standard error to mean ratio $(E)$ or confidence interval half-width to mean ratio $(D)$ with iteration

\begin{tabular}{|c|c|c|c|c|}
\hline Mean count per sample $^{+}$ & Number of samples via $(E)$ & Student's $t$ value & Number of samples via $(D)^{++}$ & Improvement in sample size \\
\hline \multicolumn{5}{|c|}{ Pratylenchus spp.: the power law parameters $a=1.58, b=1.33$} \\
\hline \multirow[t]{3}{*}{1} & \multirow[t]{3}{*}{158} & 2 (assumed) & 632 & \multirow{6}{*}{$\begin{array}{l}609 \text { and } 209 \text { instead of } 632 \text { and } \\
215 \text { samples, respectively }\end{array}$} \\
\hline & & $1.964(n=632)$ & 609 & \\
\hline & & $1.9638(n=609)$ & 609 & \\
\hline \multirow[t]{3}{*}{5} & \multirow[t]{3}{*}{54} & 2 (assumed) & 215 & \\
\hline & & $1.971(n=215)$ & 209 & \\
\hline & & $1.971(n=209)$ & 209 & \\
\hline \multicolumn{5}{|c|}{ M. incognita: the power law parameters $a=2.92, b=1.47$} \\
\hline \multirow[t]{3}{*}{5} & \multirow[t]{3}{*}{124} & 2 (assumed) & 498 & \multirow{6}{*}{$\begin{array}{l}480 \text { and } 375 \text { instead of } 498 \text { and } 388 \\
\text { samples, respectively }\end{array}$} \\
\hline & & $1.966(n=498)$ & 480 & \\
\hline & & $1.965(n=480)$ & 480 & \\
\hline \multirow[t]{3}{*}{8} & \multirow[t]{3}{*}{97} & 2 (assumed) & 388 & \\
\hline & & $1.966(n=388)$ & 375 & \\
\hline & & $1.966(n=375)$ & 375 & \\
\hline
\end{tabular}

The $t$ value is either assumed as 2 for $95 \%$ confidence interval or iterated using its tabulated value from http://www.danielsoper.com/statcalc3/calc.aspx?id=10 ${ }^{+}$Based on a sample size of $100 \mathrm{gm}$ soil (based on data reported by Abd-Elgawad et al. (2008)

${ }^{++}$The fractional values rounded up to nearest integer 


\section{Methods of application of BCAs}

Askary and Martinelli (2015) reviewed such methods. For example, Purpureocillium lilacinum formulated as a water-dispersible granule can be applied through conventional methods, using the irrigation system. Other application methods can also be used rather than suspensions of BCAs (Abd-Elgawad and Askary 2018). The suppression of $B$. longicaudatus was transferable through inoculation with gram-positive bacterium Candidatus Pasteuria usage-infested soil (Giblin-Davis et al. 2001). Moreover, the dried plant material containing sporefilled females of this mycelial endospore-forming bacterium or its separated endospores has been employed for its field introduction given its relatively cheap costs in addition to previous problems of its in vitro mass production. Currently, methods for its in vitro culture have been developed, and consequently, it is being commercialized as a biopesticide (Gerber and White 2005; AbdElgawad and Askary 2018). The bacterium achieved notable successes where a reduction in $B$. longicaudatus population densities occurred 13 months after inoculation in the field plots (Giblin-Davis et al. 2003) as well as in other field trials (Luc et al. 2010a, 2010b). Clearly, the bacterial application methods could offer good results with root-knot nematodes. Kokalis-Burelle (2015) stated three application methods of Pasteuria penetrans, seed, transplant, and post-plant treatments, for the management of $M$. incognita on tomato and cucumber and $M$. arenaria on snapdragon. Also, 3 years after, $P$. penetrans-infested dried roots transfer to another field site could bring peanut-root galling in the infested plots to as low level as those in plots fumigated with 1,3-dichloropropene (Kariuki and Dickson 2007). Using another line of thinking, BCAs are developed to act as new green soil fumigation agents. Zhai et al. (2018) found that Pseudomonas putida strain 1A00316 can act on different $M$. incognita stages via nematicidal, fumigant, and repellent activities. The strain has a potential for development as bioagent with these multiple modes for rootknot nematode (RKN) control.

$\mathrm{BCAs}$ are used in inundative biological pest control programs, but conservation biocontrol, i.e., the environmental adjustment or changing agricultural practices to protect and increase antagonistic organisms to reduce damage from PPNs, should be fostered as well. Hence, researchers should further grasp the complex network of interactions among biotic and abiotic factors in intimate contact with these BCAs to maximize their gains via safe and skillful application and advanced technology. Admittedly, nematodesuppressive soils may be a standard paradigm to follow.

\section{Environmental and biological factors}

These factors are both overlapping and may be interacting with one another. The most important ones are soil texture, moisture, temperature extremes, predation or competition, and starvation. So, it is often difficult to control these factors in the field, but one solution resides in the addition of adjuvants to enhance their efficacy. $P$. lilacinum, with the adjuvant avermectin, is utilized effectively to control PPNs (Kiewnick and Sikora 2006). Another technically advanced alternative is the use of BCA-filled capsules. Patel et al. (2002) found that encapsulating the fungus Hirsutella rhossiliensis in nutrientamended hollow beads is a promising approach to the biocontrol of PPNs. It offered the following advantages: (i) easy handling, (ii) protection from adverse environmental and biological factors, (iii) long shelf life, (iv) adequate release into the soil based on environmental conditions and capsule materials, and (v) enhancing activity in the soil. Amending capsules with adjuvants such as water-retaining substances, nutrients, and fillers should further increase efficacy. Generally, such adjuvants can enhance the key elements of their natural biocontrol strategy (dispersal, rhizosphere competition, compatibility with their new but sustainable environment, and many of the interactions with soil biota). Furthermore, micro and nanomaterial-based pesticides are one of the formulations that are increasingly considered as a suitable alternative to traditional pesticides. Yin et al. (2012) used nanocapsules of lansiumamide B by the microemulsion polymerization method to improve the nematicidal efficacy of lansiumamide B against Bursaphelenehus xylophilus and $\mathrm{J} 2$ of M. incognita. Nanoformulated agricultural inputs were recently applied to control M. incognita on tomato (El-Sherif et al. 2019), a tactic that should be further exploited.

Nevertheless, BCAs remain vulnerable to many intrinsic mortality factors in the plant rhizosphere that require further considerations (Davies and Spiegel 2011; Askary and Martinelli 2015). Such factors, singly or in combination, can result in an increased gradual decline in BCA numbers over the days following their application (Eissa and Abd-Elgawad 2015). Basically, BCAs rely mostly on their ability to proliferate or multiply in the rhizosphere intimately contacted with soil which should have suitable texture and structure for the added organism. So, soil texture and structure impact the growth and spread of microorganisms and their PPN hosts. Kerry (2000) reported that the great bulk of soil $(2500 \mathrm{t} / \mathrm{ha})$ to plow depth $(20 \mathrm{~cm})$ forms difficulty for thorough BCAs incorporation and renders uneconomic broadcast treatments. The residual soil microflora competes with the introduced BCA for scarce energy sources and can significantly affect the performance of the BCA even when it is added to soil in a pre-colonized substrate. Soil moisture rarely limits the growth of most fungi but affects spore dispersal, especially of zoospores. Bacteria are more vulnerable to moisture levels than fungi but are 
unlikely to be damaged by levels that enable PPNs to survive. As for desiccation tolerance, BCAs have different thermal limits and optima depending on their species. Temperature commands the performance and persistence of biocontrol agents. P. lilacinus requires high soil temperatures which limits its application though it is easily produced in vitro, has rhizosphere competent, can attack the PPN eggs, and practically treat seed tubers for PPN control. Soil temperatures mostly range $10-15^{\circ} \mathrm{C}$ in temperate regions for much of the growing season and $20-25^{\circ} \mathrm{C}$ in warm climates at $10-\mathrm{cm}$ depth. Such ranges have direct effects on the BCA growth and sporulation and on the PPN rate of development (Kerry 2000). Temperature can also be used as a tool to improve BCA efficacy as in entomopathogenic nematodes (EPNs) (Baiocchi et al. 2017) which could control PPNs (Jagdale et al. 2009; Abd-Elgawad 2017b). For instance, conditioning Steinernema carpocapsae and Heterorhabditis megidis for 3 weeks at $9{ }^{\circ} \mathrm{C}$ enhanced their biocontrol efficacy (Guy et al. 2017). Other abiotic and biotic interactions are worthy of interest for $\mathrm{BCA}$ predation or competition. In one sense, BCAs in soil can affect or be affected by other species, including nontarget hosts or potential competitors, especially other indigenous organisms (Askary and Martinelli 2015; Helmberger et al. 2017). As BCAs act through different modes of action such as parasitism, predation, antagonism, or competition, they may be acted on using the same or other ways by other organisms (Davies and Spiegel 2011). A strong positive correlation was found between biofumigation-induced Globodera pallida mortality and levels of microbial activity indicating that the soil microbes play a role in decreasing the nematode populations during the biofumigation (Ngala et al. 2015). Such a biofumigation, due to the release of biocidal isothiocyanates (ITCs), indicates the suppressive actions of plants in family Brassicaceae on serious plant pathogens including PPNs. Conversely, due to the adverse effect of ITCs on a wide range of soil biota including beneficial flora and fauna, unregulated liberation of ITCs may result in disrupting soil food webs and exerting negative effect on nontarget BCAs' activities and survival (Dutta et al. 2019). Therefore, agricultural practices should consider ecologically significant species and potential effect on their roles in ecosystems. This is especially important in nematode suppressive soils, where BCAs play an important role. In this vein, Labaude and Griffin (2018) stressed that the laboratory tests of susceptibility for remarkable nontargets to BCAs may not accurately foretell their real impact in the actual field conditions.

\section{Consideration of negative impact}

Safety may also be examined in terms of persistence of BCAs in the treated area and damage to human beings and the environment. Some isolates $P$. lilacinus are pathogenic to humans (Kerry 2000), but its commercial isolate P 251 demonstrated promising results regarding both potential environmental risk and biocontrol effects on PPNs (Wilson and Jackson 2013; Abd-Elgawad and Askary 2018). Hence, the interaction of BCAs with other soil biota, especially those belonging to the trophic network of their hosts, should also be considered. The added BCA may compete with indigenous organism(s) for the same resources, that is, living nematode prey or even other host(s). Consequently, the inundative use of BCAs could decrease the number of nematode prey available for inoculated BCAs, with consequences on their populations. For instance, the most direct competitors of EPNs might be nematodes themselves, either indigenous EPNs or free-living nematodes (Labaude and Griffin 2018). Because of their negative interaction on other nematodes, EPNs can be used to control PPN species (Kenney and Eleftherianos 2016).

Apart from some noticeable exceptions, such as Pasteuria spp., which have narrow host range (although this is not always the case; Mohan et al. 2012), most BCAs are capable of infecting a wide range of harmful and beneficial nematode species especially in the laboratory (Abd-Elgawad and Vagelas 2015). Yet, different species of BCAs are usually compared singly or in combination with other agricultural inputs in order to identify the best species or combination for managing definite PPN species (e.g., Timper 2014; Hammam et al. 2016; AbdElgawad 2019b; Dawabah et al. 2019). In such cases, the biocontrol processes should be carefully conceived to achieve the best matching between the various attributes of both PPNs and BCAs. For instance, egg-parasitic fungi can easily kill the eggs of root-knot nematodes but not the cyst nematodes. That is because the RKN eggs are usually exposed on the plant roots where they complete their embryonic development and hatch in the rhizosphere, but the other eggs are always protected within nematode cysts. On the contrary, nonparasitic BCAs that degrade soil amendments and release nematicidal compounds, such as the bacterium which degrades chitin to produce ammonia, are likely to kill most nematodes in soil. Similarly, many endophytic fungi may compete with a wide range of nematodes within plant roots. Therefore, PPNs which are sedentary are likely to be more vulnerable to such fungi.

Native species are often considered (e.g., Abd-Elgawad and Kabeil 2012; Shehata et al. 2019) as they are expected to be adapted to local conditions and ideally targeting the pest itself. Otherwise, successful biocontrol programs should consider the identification and deployment of highly effective strain(s) against nematode pests under specified ecological and biological conditions before their development into registered, ready-for-sale 
plant protection products. Abd-Elgawad and Kabeil (2012) pointed out that although foreign products of $T$. harzianum are available in Egypt, native strain(s) may be more adapted and less expensive without significant risk to Egyptian fauna and flora. Laboratory and greenhouse screening step are of most use in rejecting species and strains with low virulence but because many factors other than virulence are crucial to field success, it is advisable to bring more than one virulent strain to field testing (Labaude and Griffin 2018).

\section{Development of cost-effective and efficient biocontrol programs \\ Accurate evaluation of efficient biocontrol programs}

Issues and/or shortcomings related to the accurate evaluation of biocontrol agent efficacy should be avoided/solved. For instance, nematode eggs may be a better parameter of sedentary nematode reproduction such as Meloidogyne spp. than the gall index, egg mass index, or other developmental stages (Abd-Elgawad 2016b). The latter author illustrated possible weak links in a nematode's life cycle that can also be targeted for biocontrol by fungal or bacterial antagonists. He pointed out that although some researchers study only the BCA effects on their PPN targets, the efficacy of such agents on plant growth parameters and/or crop yields as the core of the issue should also be examined. Moreover, BCA efficacy is usually relied on PPN developmental parameters but assessing the activities of other markers such as pathogenesis-related proteins may be accurate and fast biochemical alternatives in host plants for PPN infection and reproduction (Abd-Elgawad 2016b).

Synergistic combinations against plant-parasitic nematodes Also, IPM programs in ways that make BCAs complementary or superior to chemical nematicides should further be explored. For instance, bionematicides can act synergistically or additively with other inputs in integrated nematode management programs. Relevant information has been reported (Abd-Elgawad and Askary 2018). For example, tomato growth parameters showed better $(P \leq 0.05)$ increase, when $P$. fluorescens GRP3 was combined with organic manure for $M$. incognita control than using either $P$. fluorescens or organic manure alone. Such approaches for additive or synergistic incorporation of BCAs with proper inputs should be tested further and broadly disseminated for true and successful transformation and better penetration of bionematicide markets. Clearly, the combined use of BCAs and other pesticides should be practiced on a wider basis.

Moreover, additional avenues to expand the commercial applications of BCAs comprise fitting them into existing or emerging IPM strategies. Therefore, the right identification for the set of circumstances that help their fitting into crop management strategies to replace the less safe chemicals should be grasped. For instance, fenamiphos was the primary chemical nematicide used on golf courses for many years in Florida, USA, but the Environmental Protection Agency has assessed the real risks of fenamiphos, especially for water resources (Keigwin 2014). Also, 1,3-dichloropropene can be used for PPN management on golf courses. Yet, its use is limited by geological restrictions, reentry, and buffer (Crow 2014). So, it has limited use (once per year) which results in short B. longicaudatus population reduction period. Hence, additional PPN management strategies included applying biologically derived alternatives to fenamiphos (Crow 2005) or a commercial formulation of $B$. firmus. Late winter/early spring utilization of this bacterium is an effective biopesticide for $B$. longicaudatus control on golf course bermudagrass (Crow 2014).

\section{Developed techniques for BCAs against PPNs}

Additional formulation and application methods should be continuously developed to offer effective and/or inexpensive biocontrol programs. Improved application tactics that may be further tested for PPN control include spraying BCAs on the plant rhizospheres, putting them in "tea bags" as a slow release system, or dipping seedling roots into BCA suspensions (Askary et al. 2017; Abd-Elgawad 2019b). These techniques also cut short the volume/amount of BCAs which consequently save costs. Yet, a good level of protection against PPN pests is maintained. Therefore, chances that expedite their useful incorporation into pest management and crop protection systems should be exploited, especially with the new and compatible application methods.

Definitely, BCAs have a place of their own as safe bionematicides, but we need them for more pest control approaches. This is especially important, since there are other bionematicides which are or are likely to become widely available soon. So, a continuous and wide searching for key commercial products and recent developments in their efficacy, commercialization, and price should be a priority concern for stakeholders. Concerning available bionematicides worldwide, in many developing countries, particularly parts of Asia, Africa, and Latin America, there are many modest industries using inexpensive labor to produce microbial products at low charges mostly for local markets, but some of them are targeted to export.

\section{Registration of new BCAs against PPNs}

Wilson and Jackson (2013) acknowledged that many of the biocontrol products are efficacious against PPNs. Yet, most of these products have not usually been subjected to the rigorous and costly registration processes needed in Europe and North America. This might be 
another reason, in addition to cheap labor, for their low costs. Therefore, the end-users, i.e., farmers, agricultural investors, and grower cooperatives should carefully look for effective and inexpensive products. Now, some governmental institutions and small companies market several types of such biocontrol products for inexpensive application, compared with chemical nematicides, in different agricultural systems (Table 2). Many of these products are claimed against all major groups of PPNs. Furthermore, some of these products contain bacteria or fungi that are also sold as plant growth promoters, plant strengtheners, or soil conditioners but not exclusively as nematicides. For example, the product Stanes sting which has a plant growth promoting rhizobacterium could act as a nematicide too (Hammam et al. 2016). Although such products may promote plants' ability to tolerate or withstand nematode attack, they are not originally nematicides. In addition, a few chemical nematicides may be produced by living organisms. For instance, Syngenta sells the nematicide abamectin which is produced during the fermentation of the actinomycete Streptomyces avermitilis. However, the company thoroughly purifies such an active ingredient (abamectin) prior to sale. Hence, the compound is registered as a pesticide, and its products are sold as chemical nematicides rather than biological controls (Wilson and Jackson 2013).

All the abovementioned lines of thinking are substantial to seize more significant share in the biopesticide market especially at developed countries. Factually, they have, usually locally, contributed in inexpensive and likely effective bionematicides (Table 2) which are being marketed in lower value broad acre crops. These may include, for example, maize, tomato, eggplant, squash, watermelon, and cucumber in Egypt. That will make their usage far more affordable to a far greater number of stakeholders and end users. However, there is little publicly available, independent efficacy data for most bionematicide products in their specified markets, and generation of such data should also be a research priority.

\section{Genetic improvement for better and broader PPN control Molecular tools to utilize BCAs against PPNs}

Research has succeeded to isolate, screen, and utilize BCAs against PPNs (e.g., Askary and Martinelli 2015; Abd-Elgawad and Askary 2018), but additional efforts should offer technologies that are truly transformational and result in significant penetration to the bionematicides market. Topalović et al. (2019) used molecular tools to reveal the bacteria with the highest affinity to attach to Meloidogyne hapla- $\mathrm{J}_{2}$ and could elucidate the dynamics and speed of the bacterial adhesion to nematode cuticle during the biocontrol process. They reported that most of the tested bacterial attackers significantly decreased the nematode penetration into the root system, demonstrating their biocontrol role in soil suppressiveness against $M$. hapla on tomato plants. Simple approaches of morphometric identification of nematode populations of a certain species may serve as a rapid basis for their management and distinguishing populations that relate to host range or virulent to resistance gene. Yet, developing molecular technology and tools should be used to address difficult applied and fundamental questions. For example, metabarcoding has great potential to characterize soil communities of nematodes and their natural enemies at lower cost and greater accuracy (because species specific tools are not required) than use of real-time polymerase chain reaction. Yet, further methodology optimizations in DNA extraction, amplification, and library preparation are needed. Moreover, the actual annotated nematode genome should be extensively studied to offer a complete resource for transcriptome, biochemical markers, effectorome, and proteome data (Juvale and Baum 2018).

\section{Molecular tools for plant resistance}

Likewise, conventional breeding for plant resistance is important, but transgenic plants have become more common and they allow for reforms that simply are not

Table 2 Key commercially available bionematicides and chemical nematicides, their applications rates, and prices in Egypt

\begin{tabular}{|c|c|c|c|}
\hline Active ingredient & Product name & $\begin{array}{l}\text { Application rate } \\
\left.\text { (product/units ha }^{-1}\right)^{+}\end{array}$ & $\begin{array}{l}\text { Price per } \\
\text { feddan }\end{array}$ \\
\hline $\begin{array}{l}10^{9} \mathrm{CFU} / \mathrm{ml} \text { of Serratia sp., Pseudomonas sp., Azotobacter sp., Bacillus circulans, and B. } \\
\text { thuringiensis }\end{array}$ & Micronema & 30 L/feddan (thrice)/year & L.E. 600 \\
\hline $10^{8}$ units/ml P. lilacinus & Bio-nematon & $2 \mathrm{~L} / \mathrm{feddan} /$ year & L.E. 500 \\
\hline $10^{9}$ bacterium cells of Serratia marcescens $/ \mathrm{ml}$ water & Nemaless & 10 L/feddan (thrice)/year & L.E. 600 \\
\hline Cadusafos (O-ethyl S,S-bis (1-methylpropyl) phosphorodithioate) & Rugby $10 \mathrm{G}$ & $24 \mathrm{~kg} / \mathrm{feddan}$ & L.E. 6480 \\
\hline Oxamyl (methyl 2-(dimethylamino)-N-(methylcarbamoyloxy)-2 oxoethanimidothioate) & Vydate $24 \%$ SL & $4 \mathrm{~L} /$ feddan (twice)/year & L.E. 2800 \\
\hline
\end{tabular}

There are broad host range claims by the manufacturer's product labels which have not necessarily been confirmed in independent trials

${ }^{+}$Figures given for comparative purposes when products are uniformly applied to citrus soil (except oxamyl for foliar application too). For some products and other, including low-value crops, product may be incorporated into field soil, potting mix, or applied in greenhouses for which different rates apply (Wilson and Jackson 2013; Hammam et al. 2016) 
possible with conventional methods. In this respect, in addition to the aforementioned negative impacts of the excessive use of nematicides, resistance-breaking nematode pathotypes have been seriously developing. Such pathotypes are regarded as virulent phenotypes or populations. A practical and safe way for the nematode control is to use nematode-resistant cultivars. It can enhance crop yields, suppress nematode populations, and support efficient rotation systems. However, such specific pathotypes can rob these advantages of resistant cultivars. For example, a few potato cyst nematode (PCN, Globodera spp.) populations are able to multiply on a set of differential potato clones/cultivars carrying different resistance genes. Plant genes for nematode resistance ( $\mathrm{R}$ genes) are assigned to the recognition of the presence of nematode avirulent factors. The loss of this trait leads to the failure of pest recognition by the resistant potato clones/cultivars and consequently develops such virulent populations. Molecular tools and techniques to differentiate such Globodera isolates should be developed (e.g., Molinari 2012) to promote the use of resistant cultivars. Likewise, RKNs have definite set of proteins that determine the virulence in plant species. The secretomes (set of secreted proteins through the nematode stylets) can elucidate a number of effector proteins that are engaged in compatible (vs. incompatible) plant-nematode interactions where suppression (vs. stimulation) of defense mechanisms of susceptible (vs. resistant) plants occurs. Breaking this rule and without tying to the present resistance response in incompatible plant-RKN interactions, a considerable number of inoculated nematode-J2 could establish feeding sites and succeeded to develop to adult females on the resistant plant genotypes forming resistance-breaking pathotypes. Therefore, another research priority is to further highlight the processes involved in the induction and formation of plant nurse cells (for RKNs) and syncytium (for cyst nematodes). Effector proteins are identified either as suppressing or stimulating plant defenses against these PPNs. Yet, their functional characterization should also be realized (Juvale and Baum 2018) for better grasping of nematode capability to parasitize and damage the plant. This is especially important since the gene expression of selected beneficial traits such as plant resistance or tolerance to nematodes at high temperature is not stable. Moreover, adequate molecular markers of plant resistance to PPNs should be explored for unique pathogen/host systems to designate host suitability. Such markers should address the most economically important nematodes which would save money, effort, and time. Enzymatic markers are promising for use as genetically based biochemical markers (Abd-Elgawad and Molinari 2008). More sensitive, rapid, and accurate electrophoretic methods, such as those that are possible with miniaturized and automated equipment, should further facilitate identification of desirable markers. Clearly, more research is needed for effective transfer of cloned genes into nematode-susceptible plant species to integrate resistance/tolerance to such PPNs. While tightly linked markers must be utilized to monitor introgression, analysis of the chromosomal region concerned should be made to explore any unexpected linkage drag. This should be accompanied by using the most up-to-date techniques of gene transfer for nematode resistance (Abd-Elgawad and Molinari 2008). Advancement in developing accurate host suitability designations with relevant resistant plants against definite PPN species will probably leverage the role of BCAs against other nematodes.

\section{Awareness-raising and grower acceptance of $\mathrm{BCAs}$}

Basically, BCAs fit the model of chemical nematicides poorly. Admittedly, BCAs are frequently slower acting, less effective, and more inconsistent than control normally achieved with chemicals. Therefore, a change in mindset away from recent technologies which use the traditional chemical pesticide model is desperately needed. Such a shift should be adopted by programs which cover various facets of awareness-raising of farmers and extensions of biologicals as bionematicides. Abd-Elgawad (2019a) suggested that these programs should include information days, targeting farmers, and extensions to transfer knowledge, technologies, and methodologies in terms of BCAs-related issues and relevant data gained hitherto. Hence, carefully conceived events should be held where field demonstration trials are practiced aiming at informing (via broad and deep training) farmers and stakeholders about the significance, application methods, mode-of-actions, and impact of BCAs on nematode pests, crops, and soil health. Meanwhile, main components and principles of effective integrated pest control projects should be discussed. These may include prophylactic production practices, other pest control techniques/measures, and crop rotations as well as answering relevant queries raised by farmers. For instance, as bionematicide market uptake increases, growers are likely to ask nematologists, extension workers, and biological control practitioners about the relative merits of chemical versus biological control (Wilson and Jackson 2013). Therefore, researchers should illustrate that biological control of PPN pests reflects wise use of natural methods and most sustainable approach for nematode management with consequent increase in growth parameters of the crop as in Fig. 1. Consequently, it should be exploited as best we can via safe and skillful application and advanced technology. 


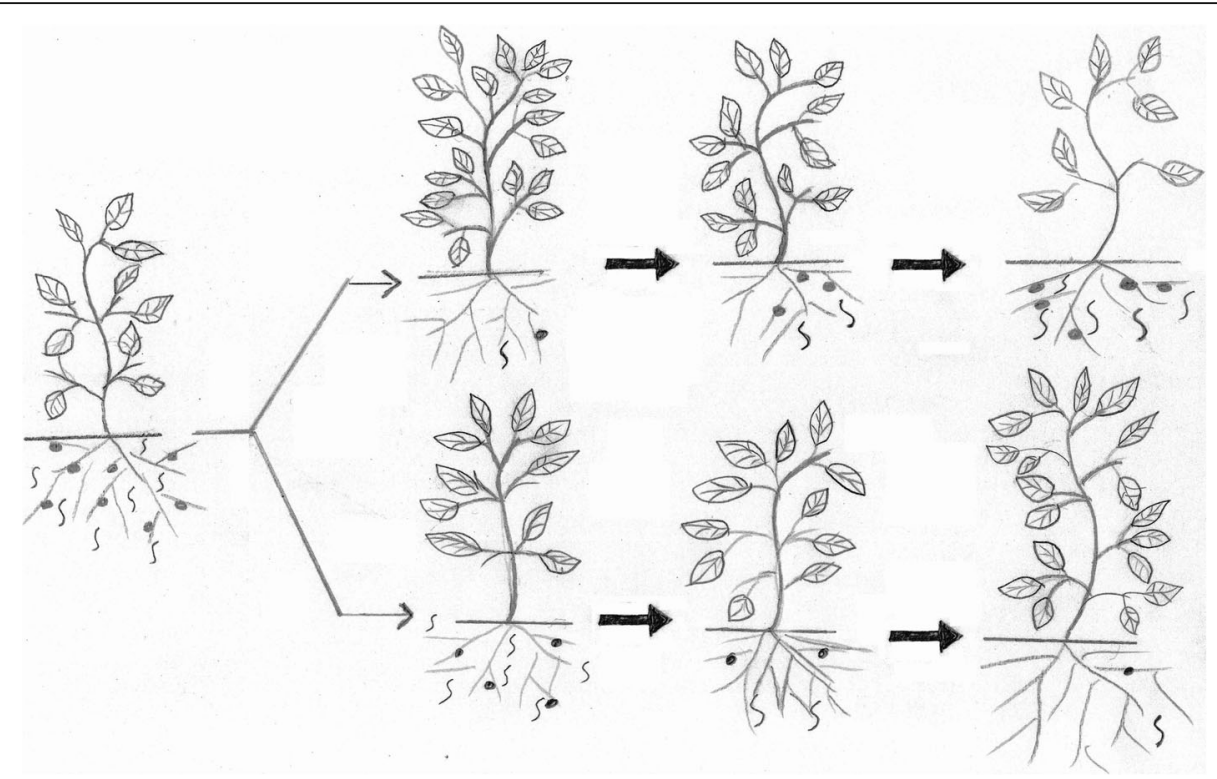

Fig. 1 Effect of a chemical nematicide (upper trend) and a bionematicide (lower trend) on root-knot nematodes on susceptible plants. On applying both nematicides, the chemical has rapid and significant effect on reducing the nematode population, but a few nematodes can escape its effect and reproduce to reach damaging level while the bionematicide can work continuously to keep the nematode below the economic threshold level

Moreover, an alternative approach to BCAs' production is to teach them simply how to grow their own microbial pesticides via "do-it-yourself" technology. Technical skills and guidelines of modern technologies to manage important PPNs should also be demonstrated.

Dissemination of knowledge and updated advances in BCAs' technology/methodology should be transferred to both farmers and extension officers during information days (Abd-Elgawad 2019a). Questionnaires may also be done to appreciate the acceptance of participants of BCAs which were tested. Relevant flyers comprising such results should be circulated. Because of the importance of mass media in the enlightenment and providing culture to the public about BCAs production, formulation, storage, packaging, and application, establishing more international internet websites may be erected. Relevant projects and BCAs' producing companies may adopt its operation aiming at increasing the number of people interested in the activity and goals of biological control against PPN pests in order to gain clean and safe agricultural produce. Moreover, the internet pages should present the more complicated criteria used for measuring effectiveness of BCAs. It is also worth considering whether anything less than perfect produce is permissible to avoid the use of hazardous chemicals. Eventually, the newly introduced paradigm of these biologicals is essential for enhancing broader use of bionematicides. An out of mold thinking should be practiced.

\section{Conclusion}

Plant-parasitic nematodes pose real threats to many economically important crops, which necessitated their control via various approaches. The use of BCAs against PPNs is particularly timely given the negative impact of the use of chemical nematicides. However, BCAs are frequently slower acting, less effective, and more inconsistent than control normally achieved with chemicals. Therefore, a better grasping of the relevant edaphic and biological factors of BCAs is likely to give new directions in their use against PPNs. Such factors were reviewed in order to maximize their useful applications against PPNs. Continuous long-term research combining laboratory tests, followed by field experiments are still needed for more optimization of BCAs used in PPN. Such studies should exploit new technologies and resources that are becoming central to the development of sustainable systems for nematode management. For example, an integrated approach consisting of a lower dose of pesticide in conjugation with compatible bionematicide(s) coupled with appropriate cultural practice may be a good option needed to develop an economically viable and ecologically sustainable management of the nematodes. Improved and standardized sampling should be exercised. Genetic improvement of BCAs should address their efficacy and allocating markers of beneficial genes. Awarenessraising for enhancing grower acceptance of biocontrol tactics should be better communicated. 


\section{Abbreviations}

BCAs: Biological control agents; PPN: Plant-parasitic nematode; EPNs: Entomopathogenic nematodes; RKN: Root-knot nematode; IPM: Integrated pest management; ITCs: Isothiocyanates

\section{Acknowledgements}

This study was supported in part by the US-Egypt Project cycle 17 (no. 172) entitled "Preparing and evaluating IPM tactics for increasing strawberry and citrus production." This article is derived from the Subject Data funded in part by NAS and USAID, and that any opinions, findings, conclusions, or rec ommendations expressed in it are those of the authors alone, and do not necessarily reflect the views of USAID or NAS. The facilities offered by The National Research Centre are appreciated.

\section{Authors' contributions}

The authors have developed and implemented this review article and written it equally. All authors read and approved the final manuscript.

\section{Funding}

Financial support made by US-Egypt Project fund for the Project cycle 17 (no. 172) and National Research Centre, Egypt, is gratefully acknowledged.

\section{Availability of data and materials}

The datasets used and/or analyzed during the current study are available from the corresponding author on reasonable request.

\section{Ethics approval and consent to participate}

Not applicable

\section{Consent for publication}

Not applicable

\section{Competing interests}

The authors declare that they have no competing interests.

\section{Author details}

${ }^{1}$ Plant Pathology Department, National Research Centre, El-Behooth St. Dokki, Giza 12622, Egypt. Division of Entomology, Sher-e-Kashmir University of Agricultural Sciences and Technology, Shalimar, Srinagar, Jammu and Kashmir, India.

Received: 15 October 2019 Accepted: 10 February 2020

Published online: 24 February 2020

\section{References}

Abd-Elgawad MMM (2016a) Use of Taylor's power law parameters in nematode sampling. Int J PharmTech Res 9(12):999-1004

Abd-Elgawad MMM (2016b) Comments on the use of biocontrol agents against plant-parasitic nematodes. Int J PharmTech Res 9(12):352-359

Abd-Elgawad MMM (2017a) Accuracy and precision of phytonematode sampling plans. Agric Eng Int CIGR J special issue: 6-15

Abd-Elgawad MMM (2017b) Status of entomopathogenic nematodes in integrated pest management strategies in Egypt. In: Abd-Elgawad MMM, Askary TH, Coupland J (eds) Biocontrol agents: entomopathogenic and slug parasitic nematodes. CAB Int, Wallingford, pp 473-501

Abd-Elgawad MMM (2019a) Towards optimization of entomopathogenic nematodes for more service in the biological control of insect pests. Egypt J Biol Pest Cont 29:77 https://doi.org/10.1186/s41938-019-0181-1

Abd-Elgawad MMM (2019b) Plant-parasitic nematodes of strawberry in Egypt: a review. Bull NRC 43:7 https://doi.org/10.1186/s42269-019-0049-2

Abd-Elgawad MMM, Abd El-Wahab AE, Koura FFH, Hammam MMA, Haroon SA (2008) Application of Taylor's power law to sample statistics of nematodes associated with cucurbits in Egypt. Egypt J Agronematol 6(2):159-170

Abd-Elgawad MMM, Askary TH (2015) Impact of phytonematodes on agriculture economy. In: Askary TH, Martinelli PRP (eds) Biocontrol Agents of Phytonematodes. CAB International, Wallingford, pp 3-49

Abd-Elgawad MMM, Askary TH (2018) Fungal and bacterial nematicides in integrated nematode management strategies. Egypt J Biol Pest Cont 28:74 https://doi.org/10.1186/s41938-018-0080-x

Abd-Elgawad MMM, Askary TH, Coupland J (eds) (2017) Biocontrol agents: entomopathogenic and slug parasitic nematodes. CAB Int, Wallingford
Abd-Elgawad MMM, Kabeil SSA (2012) Biological control of Meloidogyne incognita by Trichoderma harzianum and Serratia marcescens and their related enzymatic changes in tomato roots. Afr J Biotech 11:16247-16252

Abd-Elgawad MMM, Molinari S (2008) Markers of plant resistance to nematodes: classical and molecular strategies. Nematol Medit 36:3-11

Abd-Elgawad MMM, Vagelas IK (2015) Nematophagous bacteria: field application and commercialization. In: Askary TH, Martinelli PRP (eds) Biocontrol Agents of Phytonematodes. CAB International, Wallingford, pp 276-309

Anonymous (2019) Biopesticides market. https://www.mordorintelligence.com/ industry-reports/global-biopesticides-market-industry. Accessed 11 Oct 2019

Askary TH, Martinelli PRP (2015) Biocontrol agents of phytonematodes. CAB Int, Wallingford

Askary TH, Nermut J, Ahmad MJ, Ganai MA (2017) Future thrusts in expanding the use of entomopathogenic and slug parasitic nematodes in agriculture. In: AbdElgawad MMM, Askary TH, Coupland J (eds) Biocontrol agents: entomopathogenic and slug parasitic nematodes. CAB Int, Wallingford, pp 620-627.

Baiocchi T, Abd-Elgawad MMM, Dillman AR (2017) Genetic improvement of entomopathogenic nematodes for enhanced biological control. In: Abd-Elgawad MMM, Askary TH, Coupland J (eds) Biocontrol agents: entomopathogenic and slug parasitic nematodes. CAB Int, Wallingford, pp 505-517

Campos-Herrera R, Stuart RJ, Pathak E, El-Borai FE, Duncan LW (2019) Temporal patterns of entomopathogenic nematodes in Florida citrus orchards: evidence of natural regulation by microorganisms and nematode competitors. Soil Biol Biochem 128:193-204

Crow WT (2005) Biologically derived alternatives to Nemacur. Colf Course Manag 73(1):147-150

Crow WT (2014) Effects of a commercial formulation of Bacillus firmus I-1582 on golf course bermudagrass infested with Belonolaimus longicaudatus. J Nematol 46:331-335

Crow WT, Luc JE, Giblin-Davis RM (2011) Evaluation of Econem, a formulated Pasteuria sp. bionematicide, for management of Belonolaimus longicaudatus on golf course turf. J Nematol 43:101-109

Davies KG, Spiegel Y (2011) Biological control of plant-parasitic nematodes. Springer, Dordrecht

Dawabah AA, Al-Yahya FA, Lafi HA (2019) Integrated management of plantparasitic nematodes on guava and fig trees under tropical field conditions. Egypt J Biol Pest Cont 29 https://doi.org/10.1186/s41938-019-0133-9

Dutta TK, Khan MR, Phani V (2019) Plant-parasitic nematode management via biofumigation using brassica and non-brassica plants: current status and future prospects. Curr PI Biol 17:17-32

Eissa MFM, Abd-Elgawad MMM (2015) Nematophagous bacteria as biocontro agents of phytonematodes. In: Askary TH, Martinelli PRP (eds) Biocontrol Agents of Phytonematodes. CAB Int, Wallingford, pp 217-243

El-Sherif AG, Gad SB, Megahed A, Sergany MI (2019) Induction of tomato plants resistance to Meloidogyne incognita infection by mineral and nano-fertilizer. J Entomol Nematol 11(2):21-26

Gerber JF, White JH (2005) Materials and methods for the efficient production of Pasteuria. U.S. Patent 6(919):197 B2

Giblin-Davis RM, Williams DS, Bekal S, Dickson DW, Brito JA, Becker JO, Preston JF (2003) 'Candidatus Pasteuria usgae' sp. nov., an obligate endoparasite of the phytoparasitic nematode Belonolaimus longicaudatus. Int J System Evol Microbiol 53:197-200

Giblin-Davis RM, Williams DS, Wergin WP, Dickson DW, Hewlett TE, Bekal S, Becker JO (2001) Ultrastructure and development of Pasteuria sp. (S-1 strain), an obligate endoparasite of Belonolaimus longicaudatus (Nemata: Tylenchida). J Nematol 33:227-238

Glare TR, Caradus J, Gelernter W, Jackson T, Keyhani N, KÖhl J, Marrone P, Morin L, Stewart A (2012) Have biopesticides come of age? Trends Biotech 30:250-258

Guy A, Gaffney M, Kapranas A, Griffin CT (2017) Conditioning the entomopathogenic nematodes Steinernema carpocapsae and Heterorhabditis megidis by pre-application storage improves efficacy against black vine weevil, Otiorhynchus sulcatus (Coleoptera: Curculionidae) at low and moderate temperatures. Bio Cont 108:40-46

Hammam MMA, El-Nagdi WMA, Abd-Elgawad MMM (2016) Biological and chemical control of the citrus nematode, Tylenchulus semipenetrans (Cobb, 1913) in Egypt. Egypt J Biol Pest Cont 26(2):345-349

Helmberger MS, Shields EJ, Wickings KG (2017) Ecology of belowground biological control: entomopathogenic nematode interactions with soil biota. Appl Soil Ecol 121:201-213

Holladay BH, Willett DS, Stelinski LL (2016) High throughput nematode counting with automated image processing. BioControl 61:177-183 
Jagdale GB, Kamoun S, Grewal PS (2009) Entomopathogenic nematodes induce components of systemic resistance in plants: biochemical and molecular evidence. Bio Cont 51:102-109

Juvale PS, Baum TJ (2018) Cystained: research into Heterodera parasitism. PLoS Pathog 14(2):e1006791 https://doi.org/10.1371/journal.ppat.1006791

Kariuki GM, Dickson DW (2007) Transfer and development of Pasteuria penetrans. J Nematol 39:55-61

Keigwin RP Jr (2014) Fenamiphos: amendment to existing stocks provision of use deletion and product cancellation order. Federal Reg 79:59261-59262

Kenney E, Eleftherianos I (2016) Entomopathogenic and plant pathogenic nematodes as opposing forces in agriculture. Int J Parasitol 46:13-19

Kerry BR (2000) Rhizosphere interactions and exploitation of microbial agents for the biological control of plant-parasitic nematodes. Annu Rev Phytopath 38:423-441

Khan A, Williams KL, Nevalainen HKM (2006) Control of plant-parasitic nematodes by Paecilomyces lilacinus and Monacrosporium lysipagum in pot trials. Bio Control 51(5):643-658

Kiewnick S, Sikora RA (2006) Biological control of the root-knot nematode Meloidogyne incognita by Paecilomyces lilacinus strain 251. Bio Cont 38:179187. https://doi.org/10.1016/j.biocontrol.2005.12.006

Kokalis-Burelle N (2015) Pasteuria penetrans for control of Meloidogyne incognita on tomato and cucumber, and M. arenaria on snapdragon. J Nematol 47(3): $207-213$

Labaude S, Griffin CT (2018) Transmission success of entomopathogenic nematodes used in pest control. Insects 9:72. https://doi.org/10.3390/ insects9020072

Lehr P (2010) Biopesticides: the global market. Report code CHM029B. BCC Res

LuC JE, Crow WT, McSorley R, Giblin-Davis RM (2010a) Suppression of Belonolaimus longicaudatus with in vitro-produced Pasteuria sp. endospores. Nematropica 40:217-225

Luc JE, Pang W, Crow WT, Giblin-Davis RM (2010b) Effects of formulation and host density on the ability of in vitro-produced Pasteuria endospores to control its host Belonolaimus longicaudatus. J Nematol 42:87-90

Mohan S, Mauchline TH, Rowe J, Hirsch PR, Davies KG (2012) Pasteuria endospores from Heterodera cajani (Nematoda: Heteroderidae) exhibit inverted attachment and altered germination in cross-infection studies with Globodera pallida (Nematoda: Heteroderidae). FEMS Microbiol Ecol 79:675-684

Molinari S (2012) Resistance and virulence in plant-nematode interactions. In: Boer F, Chung JA (eds) Nematodes. Nova Sci Publisher Inc, New York, pp 59-82

Moosavi MR, Zare R (2015) Factors affecting commercial success of biocontrol agents of phytonematodes. In: Askary TH, Martinelli PRP (eds) Biocontrol Agents of Phytonematodes. CAB Int, Wallingford, pp 423-445

Ngala BM, Haydock PP, Woods S, Back MA (2015) Biofumigation with Brassica juncea, Raphanus sativus and Eruca sativa for the management of field populations of the potato cyst nematode Globodera pallida. Pest Manag Sci 71:759-769

Patel AV, Rose T, Vorlop K-D (2002) Encapsulation of Hirsutella rhossiliensis in hollow beads based on sulfoethylcellu-lose to control plant-parasitic nematodes. Landbauforschung Völkenrode 241:145-150

Shehata IE, Hammam MMA, El-Borai FE, Duncan LW, Abd-Elgawad MMM (2019) Comparison of virulence, reproductive potential, and persistence among local Heterorhabditis indica populations for the control of Temnorhynchus baal (Reiche \& Saulcy) (Coleoptera: Scarabaeidae) in Egypt. Egypt J Biol Pest Cont 29:32 https://doi.org/10.1186/s41938-019-0137-5

Timper P (2014) Conserving and enhancing biological control of nematodes. J Nematol 46:75-89

Topalović O, Elhady A, Hallmann J, Richert-Pöggeler KR, Heuer H (2019) Bacteria isolated from the cuticle of plant-parasitic nematodes attached to and antagonized the root-knot nematode Meloidogyne hapla. Sci Rep 9(1):11477. https://doi.org/10.1038/s41598-019-47942-7

Wilson MJ, Jackson TA (2013) Progress in the commercialisation of bionematicides. Bio Cont 58:715-722

Yin Y-H, Guo Q-M, Han Y, Wang L-J, Wan S-Q (2012) Preparation, characterization and nematicidal activity of lansiumamide B nano-capsules. J Integrat Agric 11(7):1151-1158

Zhai Y, Shao Z, Cai M, Zheng L, Li G, Huang D, Cheng W, Thomashow LS, Weller DM, Yu Z, Zhang J (2018) Multiple modes of nematode control by volatiles of Pseudomonas putida 1A00316 from Antarctic soil against Meloidogyne incognita. Front Microbiol 9:253. https://doi.org/10.3389/fmicb.2018.00253

\section{Publisher's Note}

Springer Nature remains neutral with regard to jurisdictional claims in published maps and institutional affiliations.

\section{Submit your manuscript to a SpringerOpen ${ }^{\odot}$ journal and benefit from:}

- Convenient online submission

- Rigorous peer review

- Open access: articles freely available online

- High visibility within the field

- Retaining the copyright to your article

Submit your next manuscript at $\boldsymbol{\nabla}$ springeropen.com 